\title{
Benjamin Bryce (2019). Ser de Buenos Aires. Alemanes, argentinos y el surgimiento de una sociedad plural 1880-1930, Biblios, Buenos
} Aires, Argentina, 340 páginas, ISBN 978-987-691-756-8

RESEÑA DE LIBRO

\author{
Por Nicolás Ezequiel González \\ Universidad de Buenos Aires. Contacto: negonzalez1993@gmail.com
}

Recibido: junio de 2020

Aceptado: septiembre de 2020

El libro de Benjamin Bryce, profesor de la Universidad de Columbia Británica en Canadá y especialista en historia comparada de la migración, surge de su investigación acerca de las comunidades alemanas en diversos puntos del continente, en particular Argentina, Estados Unidos y Canadá. Particularmente en Ser de Buenos Aires, se dedica a analizar la manera en la que los inmigrantes de esta colectividad se establecieron en el país y cómo fueron formando sus instituciones y sociabilidad mientras transcurría su existencia en esta ciudad.

Durante los años analizados dentro de este trabajo tuvo lugar en la sociedad porteña la gestación de la cultura propia de dicha ciudad. Según su hipótesis, en el proceso de gestación entraron en disputa distintas visiones sobre temas de la configuración de la identidad local, en donde se encontraban las cuestiones de la etnicidad, la cultura y cómo estos elementos constituían parte de esa identidad. En particular, el autor destaca la posición del nacionalismo criollista que asimila la argentinidad a la herencia hispánica, en la que, pensándola como una sociedad homogénea, asimilaría a los inmigrantes dentro de una cultura única, con la lengua española como la única utilizada por sus miembros. Su proyecto se canalizó mayoritariamente a través de las reformas educativas del período, a través de las cuales el proyecto de fundación de la nacionalidad tuvo lugar. Frente a ello, Bryce plantea que las comunidades extranjeras ponen en disputa esta cuestión para proponer un contraproyecto de nación pluralista donde las identidades argentinas y de su propio origen podían convivir sin excluirse entre sí. Estas actividades se encuentran en los márgenes de la acción estatal que permite su existencia, en parte también para cubrir esos ámbitos a los que no llegaba, como la asistencia social y la salud pública y tolerando otras como las escuelas pertenecientes a las distintas comunidades. Dentro de esas comunidades migrantes se dedica a estudiar a la comunidad alemana y las estrategias de conformación e integración que tuvieron para dentro de sí, haciendo foco en la división que generaba la pertenencia al credo luterano y católico en la forma en que esta se llevaba a cabo.

Ser de Buenos Aires consta de una introducción y seis capítulos, cada uno con su 
conclusión particular, además de una conclusión general.

En la introducción, el autor define la etnicidad como algo "contradictorio, circunstancial y superpuesto [...] construido en diálogo con el contexto social circundante" (p.33). Según su definición, esto se explicitaría a través de determinadas marcas como la cultura, la religión o el lenguaje. Justamente, a través de su definición de etnicidad como un concepto móvil, se hace presente uno de los conceptos centrales del libro: el bilingüismo. A partir de la cuestión idiomática, el autor transforma los usos de la lengua de estos inmigrantes y sus descendientes como una metáfora que describe la superposición de identidades étnicas, en las que la categoría de argentino y alemán se entrecruzan al interior de las identidades particulares de los sujetos. También explica a continuación su elección metodológica de la comunidad alemana:

[la comunidad alemana puede] ser un caso de estudio particularmente útil para analizar la importancia de la religión y la identidad confesional a la hora de conformar las comunidades y las identidades étnicas [...] Debido a que los católicos germano hablantes eran parte de la confesión religiosa dominante [...] pueden ilustrar cómo las identidades confesionales y étnicas se alimentaban entre sí (pp. 26-27).

Luego, delimita también a la intelectualidad argentina a un grupo que proponía la existencia de una raza hispánica frente al cosmopolitismo que introducian los inmigrantes, un nuevo nacionalismo representado por figuras como Larreta, Ugarte, Rojas y Gálvez. En contraposición a esto, los inmigrantes de diversos orígenes se oponían al hispanismo y planteaban una diferencia entre ciudadanía y raza. En el caso de la definición de lo alemán, para el autor la misma se independiza de la nacionalidad y se basa en los términos clásicos idiomáticos al estilo fichteano. Allí, es donde esboza un problema de la reproducción de dicho idioma en una sociedad que utiliza un lenguaje de otra familia lingüística y el equilibrio imperfecto entre ellos a la hora de usarlos. Finalmente, pasa revista al nacionalismo alemán, el cual utiliza a los inmigrantes para obtener influencia económica y política e introduce el concepto de Auslanddeutschtum [Germanidad en el exterior], en el que la germanidad se transmite de forma biológica pero que, paradójicamente, corre riesgo de perderse a través de las nuevas generaciones. En la conexión con Alemania, los actores locales jugaban un papel híbrido, en el que ellos buscaban ese vínculo, pero también tenían sus propias dinámicas guiadas por sus propios intereses.

En el siguiente capítulo, Bryce comienza el análisis de las instituciones de asistencia social establecidos por la comunidad de migrantes. En él, la principal tesis es que ellas daban otro significado al concepto de ciudadanía, responsabilidad social y pertenencia a la Argentina. Los inmigrantes prósperos, con el apoyo de algunas mujeres, crearon las comunidades étnicas y patriarcales a través de estas instituciones; su rol dominante se sustentaba en la dinámica de donación establecida a través de las obras caritativas. A su 
vez, el autor sostiene que los benefactores intentaban influir en la conformación social al interior de estas comunidades, influenciando el establecimiento de determinados roles como el jefe de familia que sostenía el hogar e intentando alejar a las mujeres de prácticas como el ejercicio de la prostitución, lo que mostraría que intentaban relacionarse con las nociones de respetabilidad establecidas por la sociedad argentina, como estrategia de integración a ella y de ganar acceso al prestigio social. Bryce encuentra en su proyecto la causa del desarrollo de una comunidad étnica que promovía la cohesión grupal y aseguraba la permanencia y éxito de los inmigrantes. Al mismo tiempo, la acción benéfica habría desplazado al Estado como un actor más en el campo de la asistencia social, lo que sería uno de los modos en los que los líderes participaron del establecimiento de las condiciones de pertenencia y ciudadanía en el país.

En la segunda sección, Benjamin Bryce abandona el análisis de esas instituciones y desplaza su atención a las escuelas bilingües. Estas habrían sido parte de un patrón más amplio dentro de la ciudad, donde las actividades de los inmigrantes que las patrocinaban ayudarían a la creación de un equilibrio entre ciudadanía y pluralismo cultural en la Argentina. La subversión de los significados estaba dada a partir del desafío que ellas instituciones planteaban a la concepción impulsada por los nuevos nacionalistas desde los puestos acumulados en el Estado. Frente a su proyecto, las escuelas de inmigrantes, que el autor define como bilingües en lugar de alemanas, planteaban una noción de ciudadanía basada en una sociedad plural donde la cultura alemana tenía cabida. De esa forma, la etnicidad alemana se reproducía a través de la comunidad y los educadores encontraron un equilibrio entre su estatus, las capacidades lingüísticas de sus alumnos y su propia identidad, en la que lo argentino y lo alemán tenían su espacio, característica que le permitiría identificarlas como bilingües. Los promotores escolares se establecían a la cabeza de la colectividad germanohablante, ya que la educación les permitía fundar una comunidad controlada por ellos al mismo tiempo que les otorgaba prestigio a nivel social. Por último, el autor compara los efectos del discurso liberal oficial a través de una comparación con la educación del idioma en Estados Unidos y Canadá, donde la educación del idioma alemán estaba integrada en las instituciones públicas, a diferencia de la Argentina tienen que efectuarla en espacios particulares, algo que ahonda en el siguiente capítulo.

En este apartado, comienza por definir a los directores de las escuelas bilingües como los impulsores de una definición pluralista de ciudadanía a través de la fomentación del bilingüismo. La regulación estatal estableció un sistema educativo donde la asimilación no siempre llevó a políticas eficaces, donde diversos actores sociales tenían ideas diferentes sobre la relación entre idioma y ciudadanía, que se transmitía a través de la historia, geografía y educación cívica, según la visión nacionalista y que reservaba estas esferas para docentes argentinos exclusivamente. A su vez, recapitula un debate entre reformistas y promotores de las escuelas bilingües, donde el rol del idioma también cumplía una función 
en la promoción de la unidad nacional. Esas escuelas, sin embargo, no refutaban los requisitos de la educación cívica, sino que fomentaban el bilingüismo, lo que habría permitido la ampliación de la definición de ciudadanía cultural. Así, el Estado se habría limitado a garantizar la competencia en español y las principales asignaturas mientras que la autonomía para enseñar gran parte de las asignaturas en otros idiomas mostraba los límites que tenía para imponer sus ideas a los hijos de los inmigrantes y dotaba de flexibilidad a sus regulaciones; permitiendo la integración en esas comunidades sin que eso implicara excluirlos de la nacionalidad argentina.

Ya definidas las cuestiones que hacen a las relaciones de estas escuelas con el nacionalismo argentino, el autor cambia el foco hacia las iniciativas que provenían desde Alemania. Comienza reafirmando el contacto interesado desde los educadores germanoparlantes radicados en Buenos Aires hacia el nacionalismo imperial alemán, sosteniendo que buscaban un equilibrio entre sus propias identidades étnicas y la pertenencia de sus alumnos a una sociedad hispanohablante. La autonomía otorgada creó un sistema donde los líderes tomaron los recursos provenientes de Europa, a través de ideas, financiación y profesores, que mantenían el interés en sostenerlo. Por otro lado, desde el II Reich se buscaba que la red de escuelas mantuviera a los descendientes dentro de una nación sin límites geográficos ni generacionales y para poder sostener este interés, las escuelas adoptaron la retórica sobre los peligros en los que se encontraba la germanidad. Al mismo tiempo, los alemanes pudieron obtener influencia en la región mientras que las escuelas se beneficiaban de poder definirse "alemanas" a pesar de su estatus bilingüe. Los padres y educadores también se apropiaron de la retórica del peligro impulsada desde Alemania y gracias a ello también impulsaron la formación de la relación transatlántica, subvirtiendo la idea de la homogeneidad de la nación argentina y debilitando la noción pura de germanidad o Deutschtum impulsada desde Berlín.

Finalmente, en los últimos dos capítulos se pasa al análisis de las identidades religiosas que habrían ayudado a definir los límites al interior de la comunidad alemana y su manera de relacionarse con la sociedad circundante. En primer lugar, sostiene que las personas y el dinero circulaban a través del Atlántico según las líneas confesionales, en parte impulsadas por los grupos radicados en Europa que buscaban contactarse con los emigrantes. Aquí se diferencian las concepciones de luteranos y católicos sobre los conceptos de etnicidad, comunidad y pertenencia en Argentina y Alemania. La preocupación por la pérdida del idioma movilizaba particularmente a los luteranos que temían por la conversión al catolicismo y que sería el factor crucial del envío de fondos. A su vez, también estas divisiones afectaban a las instituciones surgidas en Argentina y las conexiones que establecían, algo que continúa en el siguiente capítulo.

En el último apartado, después de repetir que las competencias lingüísticas y la religión eran los pilares de la creación de la etnicidad y que los inmigrantes hacen foco en ellos para hablar de sus descendientes, diferencia a los luteranos y católicos. Los primeros, 
organizaron su identidad en diálogo con la sociedad católica e hispanoparlante que los rodeaba y se interesaron más en el mantenimiento de la lengua y la transmisión de la etnicidad a través de la enseñanza del idioma y la religión, algo que el autor encuentra ejemplificado en la construcción de orfanatos para los niños de la comunidad, además de la preocupación por la relación a establecer con el español dentro de sus ritos. Por otro lado, la fracción católica mostró un interés más limitado por los problemas del idioma, ya que para ellos ésta solo era un vehículo y no tenía un rol clave en la reproducción de la etnicidad. En cambio, ellos estaban supeditados a las preocupaciones del catolicismo en general durante la secularización del período liberal. Sin embargo, concluye que ambos se integraron a la sociedad argentina en los debates sobre estos temas y se esforzaron por erigir un espacio para su visión de arraigo que amplió el significado de ciudadanía en Argentina.

En mi opinión, la obra de Benjamin Bryce es un aporte original al estudio de las comunidades germanoparlantes en la Argentina, en gran parte gracias al uso de fuentes de orígenes variados que realiza el autor; entre ellas pueden encontrarse archivos de las instituciones locales, así como también una selección muy diversa de aquellas que abordaban esos temas desde Europa. A propósito, también considero que el concepto de bilingüismo es útil para lograr una mejor comprensión de las relaciones entre las diversas identidades de los sujetos y cómo éstas pueden relacionarse entre sí, demostrando efectivamente cómo se modifican entre ellas en el proceso. Por otro lado, la exposición de los temas permite diseccionar bien las aristas de la identidad que el autor intenta analizar y hace que pueda enfocarse en la forma en la que ellas se relacionan, aunque esto haga que luego sea difícil trazar la periodicidad de los procesos allí descritos. Así, se complejiza la comprensión de su devenir durante el período de tiempo en el que se desarrollan e impide entrever las relaciones que trazaron gobiernos de colores políticos tan diversos como Roca e Yrigoyen y contextos como la Belle Époque y la Primera Guerra, la cual, siguiendo los aportes de Ronald Newton (1995), habría tenido un impacto mayúsculo sobre la comunidad al ubicarse la Argentina alineada en favor de Gran Bretaña y sus aliados, lo que dio lugar a la aparición de sentimientos antialemanes en la población y conllevó pérdida de empleos y discriminación.

En conclusión, Ser de Buenos Aires es una obra que presenta una problemática de manera tal que introduce nuevas perspectivas sobre cómo las comunidades migrantes se adaptaron a la sociedad porteña en construcción y cómo ambas fueron constituyéndose en diálogo mutuo. Esto permite incorporar nuevas preguntas sobre las cuestiones que hicieron a la formación de esa sociabilidad y de las identidades en general. 